\title{
Zoledronate suppresses VEGF-induced capillary tube formation and inhibits expression of interferon-induced transmembrane protein-1 in human umbilical vein endothelial cells
}

\author{
BEOM SU KIM ${ }^{1,2}$, SUN-SIK YANG ${ }^{2}$, CHEOL-SANG KIM ${ }^{1}$ and JUN LEE ${ }^{2,3}$ \\ ${ }^{1}$ Carbon Nano Convergence Technology Center for Next Generation Engineers, Chonbuk National University, \\ Jeonju, North Jeolla 54896; ${ }^{2}$ Bonecell Biotech Inc., Daejeon, South Chungcheong 302-830; \\ ${ }^{3}$ Wonkwang Bone Regeneration Research Institute, Wonkwang University, Iksan, North Jeolla 570-749, Republic of Korea
}

Received July 26, 2017; Accepted January 31, 2018

DOI: $10.3892 / \mathrm{ijmm} .2018 .3497$

\begin{abstract}
Interferon-induced transmembrane protein 1 (IFITM1) is a member of the interferon-induced transmembrane protein family and has recently been identified as a novel protein participant in angiogenesis. Zoledronate (ZON), a nitrogen-containing bisphosphonate, is widely used in the treatment of osteoporosis and to prevent bone metastases of certain cancer types. However, the association between $\mathrm{ZON}$ and IFITM1 has remained elusive. The present study investigated the effect of ZON on the expression of IFITM1 during vascular endothelial growth factor (VEGF)-induced capillary tube formation in human umbilical vein endothelial cells. It was observed that cell proliferation and VEGF-induced tube formation were significantly inhibited by treatment with $10 \mu \mathrm{M}$ ZON. The expression of IFITM1 increased during VEGF-induced tube formation. However, the VEGF-induced increase in IFITM1 expression exhibited a dose- and time-dependent decrease with ZON treatment at the mRNA and protein level. Furthermore, matrix metalloproteinase- 9 activation was markedly decreased by $\mathrm{ZON}$ treatment. These results suggest that induction of IFITM1 expression may be involved in the anti-angiogenic activity of ZON.
\end{abstract}

Correspondence to: Professor Jun Lee, Wonkwang Bone Regeneration Research Institute Wonkwang University, 460 Iksandaero, Iksan, North Jeolla 570-749, Republic of Korea

E-mail: omslee@wku.ac.kr

Professor Cheol-Sang Kim, Carbon Nano Convergence Technology Center for Next Generation Engineers, Chonbuk National University, College of Engineering Building 9, 567 Baekje-daero, Jeonju, North Jeolla 54896, Republic of Korea

E-mail: cskim@jbnu.ac.kr

Key words: interferon-induced transmembrane protein 1, angiogenesis, vascular endothelial growth factor, tube formation, endothelial cell

\section{Introduction}

Bisphosphonate-related osteonecrosis of the jaw (BRONJ) is a newly reported disease. The first cases of BRONJ associated with the use of oral bisphosphonates (BPs) were reported in 2003 (1). Most of the reported cases were of patients who had received intravenous BPs, including alendronate, zoledronate (ZON) and ibandronate $(2,3)$. Numerous studies have attempted to identify the pathogenesis of $\operatorname{BRONJ}(2,3)$. In addition to hard tissue disturbance and immune system disorders caused by BPs, the anti-angiogenic action of BPs was also reported as a possible pathological mechanism of BRONJ $(4,5)$. The anti-angiogenic theory states that the inhibition of neo-angiogenesis by BPs leads to a loss of blood vessels in bone tissue and avascular necrosis (1). Although numerous molecules are known to be associated with the cellular mechanisms of angiogenesis (6), they have remained to be fully elucidated.

Angiogenesis, the formation and growth of new capillary blood vessels, is an important process in numerous physiological conditions, including embryonic development and wound healing. A previous study reported that ZON, a new-generation BP with a heterocyclic imidazole substituent, is a potent inhibitor of angiogenesis (7). This study also demonstrated that ZON inhibited the proliferation and regulated the adhesion and migration of endothelial cells. Furthermore, Yamada et al (8) reported that $\mathrm{ZON}$ inhibited angiogenic processes, including capillary tube formation.

Interferon-induced transmembrane protein 1 (IFITM1), also known as 9-27, CD225 or Leu 13, is a member of the IFITM family. The protein is a cell surface molecule with several molecular functions, including cell adhesion and proliferation. In particular, the IFITM1 protein has been identified as an antiviral restriction factor for influenza A virus replication (9) and is overexpressed in several types of cancer, including colorectal, gastrointestinal, head and neck, and breast cancer (10-12). A recent study demonstrated that human IFITM1 regulates angiogenesis in human endothelial cells (13). However, the possible implication of IFITM1 in the anti-angiogenic activity of ZON has remained to be elucidated. Therefore, the purpose of the present study was to investigate 
the association between the anti-angiogenic activity of ZON and the IFITM1 protein in human umbilical vein endothelial cells (HUVECs).

\section{Materials and methods}

Cell culture. Immortalized HUVECs were purchased from the American Type Culture Collection (Manassas, VA, USA) and maintained in Dulbecco's modified Eagle's medium (DMEM) supplemented with $10 \%$ fetal bovine serum (both from Gibco; Thermo Fisher Scientific, Inc., Waltham, MA, USA and antibiotics. The cells were cultured at $37^{\circ} \mathrm{C}$ in a humidified atmosphere with $5 \% \mathrm{CO}_{2}$.

Cell proliferation assay. The cells were seeded in 96-well plates at $3 \times 10^{3}$ cells/well. After $24 \mathrm{~h}$, the culture medium was replaced with medium containing ZON (1 nM-10 $\mu \mathrm{M})$ and/or vascular endothelial growth factor (VEGF; $10 \mathrm{ng} / \mathrm{ml}$; Sigma-Aldrich; Merck KGaA, Darmstadt, Germany). After incubation for 3 days, cell proliferation was analyzed by using an MTS assay kit. The absorbance was measured at $490 \mathrm{~nm}$ on a microplate reader (Spectra MAX M3; Molecular Devices, Sunnyvale, CA, USA) and the changes in cell proliferation were expressed as a percentage of the mean value of the control (untreated cells).

Matrigel tube formation assay. To determine capillary tube formation, a Matrigel tube formation assay was performed. The prepared liquid Matrigel (BD Biosciences, Franklin Lakes, NJ, USA) was added into a 96-well culture plate at $70 \mu \mathrm{l} /$ well and allowed to polymerize for $1 \mathrm{~h}$ at $37^{\circ} \mathrm{C}$. Prior to the tube formation assay, the HUVECs were cultured in serum-free medium for $24 \mathrm{~h}$, seeded on Matrigel ( $3 \times 10^{4}$ cells/well) with VEGF or various concentrations of $\mathrm{ZON}$, and then incubated at $37^{\circ} \mathrm{C}$ for $24 \mathrm{~h}$. Subsequently, tube formation was observed under a microscope (DM IL LED Fluo; Leica Microsystems, Wetzlar, Germany) and the total tube length was measured by using Image Pro Plus 6.0 software (Media Cybernetics, Rockville, MD, USA).

Western blot analysis. Western blot analysis was used to detect IFITM1 expression. In brief, cells were grown in serum-free DMEM for $24 \mathrm{~h}$ and then treated with VEGF or various concentrations of $\mathrm{ZON}$. The total protein was subsequently obtained by using a cell lysis buffer (iNtRon Biotechnology; Seongnam, Korea). The protein concentrations of the sample were determined using a BCA protein assay kit (Thermo Fisher Scientific, Inc.) and equal amounts $(50 \mu \mathrm{g})$ of protein were loaded, separated by $12 \%$ SDS-PAGE and transferred onto a nitrocellulose membrane (GE Healthcare; Little Chalfont, UK). The membranes were blocked with $1 \%$ bovine serum albumin (Sigma-Aldrich; Merck KGaA) in $50 \mathrm{mM}$ Tris (pH 7.5) containing $100 \mathrm{mM} \mathrm{NaCl}$ and $0.1 \%$ Tween-20, and incubated with the primary antibody, anti-IFITM1 (cat. no. 13126S; dilution 1:1,000; Cell Signaling Technology, Inc., Danvers, MA, USA) for $3 \mathrm{~h}$ at room temperature. After extensive washing in TBS and $0.1 \%$ Tween-20, the horseradish peroxidase-conjugated secondary antibody (cat. no. 7074S; dilution 1:5,000; Cell Signaling Technology, Inc.) was added and the membranes were incubated for a further $1 \mathrm{~h}$ at room temperature. Finally, the membrane was visualized by using an enhanced chemiluminescence kit (GE Healthcare).
Reverse transcription-quantitative polymerase chain reaction $(R T-q P C R)$. To determine the mRNA expression of IFITM1, total mRNA was extracted using an RNA isolation kit (Ribospin II; Gene All, Seoul, Korea), and complementary DNA was synthesized by reverse transcriptase (RT) with oligo(dT) primers using Accu Power ${ }^{\circledR}$ RTPre Mix (Bioneer Corporation, Daejeon, Korea). The sequences of the primers used for this application were as follows: IFITM1 forward, 5'-AGCCAGAAGATGCACAAGGA-3' and reverse, 5'-GAT CACGGTGGACCTTGGAA-3'; $\beta$-actin forward, 5'-AATGCT TCTAGGCGGACTATG-3' and reverse, 5'- TTTCTGCGC AAGTTAGGTTTT-3'. Real-time PCR was performed using an ABI Step One Plus ${ }^{\mathrm{TM}}$ machine (Applied Biosystems; Thermo Fisher Scientific, Inc.) with SYBR-Green (Fast SYBR ${ }^{\mathrm{TM}}$-Green Master mix; Applied Biosystems). Thermocycling conditions were as follows: Initial denaturation at $95^{\circ} \mathrm{C}$ for $10 \mathrm{~min}$ for 1 cycle, followed by denaturation at $92^{\circ} \mathrm{C}$ for $15 \mathrm{sec}$ and annealing/extension at $60^{\circ} \mathrm{C}$ for $30 \mathrm{sec}$, repeated for 40 cycles. The data were normalized to the geometric means of the reference gene $\beta$-actin using a comparative $\Delta \Delta \mathrm{Cq}$ method (14).

Zymography. To analyze matrix metalloproteinase (MMP-9) activation, gelatinase zymography was used. Gelatinolytic activity of VEGF or/and ZON was visualized on SDS-PAGE gels $(10 \%$ polyacrylamide) containing $1 \mathrm{mg} / \mathrm{ml}$ gelatine (Sigma-Aldrich; Merck KGaA). The gels were soaked in $2.5 \%$ Triton X100 (Sigma-Aldrich; Merck KGaA) for $40 \mathrm{~min}$ at $37^{\circ} \mathrm{C}$, and incubated in $50 \mathrm{mM}$ Tris- $\mathrm{HCl}$ (pH 7.5) with $10 \mathrm{mM} \mathrm{CaCl}_{2}$ and $10 \mathrm{mM} \mathrm{NaCl}$ overnight at $37^{\circ} \mathrm{C}$, followed by staining with Coomassie brilliant blue (Sigma-Aldrich; Merck KGaA). The zymography results were quantified using Image J software version 1.37a (National Institutes of Health, Bethesda, MD, USA).

Statistical analysis. All experiments were performed a minimum of three times. The values are expressed as the mean \pm standard deviation. Statistical analyses were performed with GraphPad Prism version 5.3 (GraphPad Software, Inc., La Jolla, CA, USA). Significant differences among groups were identified by one-way analysis of variance followed by Dunnett's multiple comparisons test. $\mathrm{P}<0.05$ was considered to indicate a statistically significant difference.

\section{Results}

ZON inhibits VEGF-induced HUVEC proliferation. To investigate the effects of $\mathrm{ZON}$ on vascular endothelial cell proliferation, the viability of HUVECs treated with various concentrations of ZON (10 $\mathrm{nM}-10 \mu \mathrm{M})$ in the presence of VEGF was first analyzed. The cell proliferation was significantly increased by $10 \mathrm{ng} / \mathrm{ml}$ VEGF $(252.1 \pm 23.17 \%)$. ZON (10 nM-1 $\mu \mathrm{M})$ did not significantly alter the VEGF-induced proliferation. However, the proliferation was inhibited by $10 \mu \mathrm{M}$ ZON (150.2 $\pm 7.7 \%$ ) (Fig. 1). These results indicated that ZON inhibited VEGF-induced HUVEC proliferation in vitro.

ZON inhibits VEGF-induced tube formation. To evaluate the effects of ZON on tube formation, tube formation in Matrigel was evaluated after treatment with VEGF and/or ZON. The levels of endothelial cell capillary tube and network formation were markedly increased by $10 \mathrm{ng} / \mathrm{ml}$ VEGF ( 2-fold). 
Although tube formation was not significantly affected by $10 \mathrm{nM}-1 \mu \mathrm{M}$ ZON (data not shown), the VEGF-induced tube formation of HUVECs was strongly suppressed by $10 \mu \mathrm{M}$ $\mathrm{ZON}$ (Fig. 2). These results indicated that $\mathrm{ZON}$ inhibited VEGF-induced capillary tube formation by HUVECs.

Effect of ZON on IFITM1 expression. The involvement of IFITM1 in ZON-induced inhibition of cell proliferation and tube formation was then explored. Fig. 3A and B presents IFITM1 protein expression after treatment with $10 \mu \mathrm{M} Z \mathrm{ZON}$ for 24, 48 and $72 \mathrm{~h}$. Furthermore, the relative IFITM1 mRNA expression determined by RT-qPCR is presented in Fig. 3C. In the absence of ZON, IFITM1 was expressed at basal levels. However, IFITM1 protein and mRNA expression was significantly decreased by $\mathrm{ZON}$ in a time-dependent manner. These results indicated that IFITM1 expression was inhibited by treatment with ZON. By contrast, IFITM1 expression was enhanced by VEGF treatment for $24 \mathrm{~h}$.

ZON inhibits VEGF-induced tube formation and IFITMI expression. To confirm the effect of ZON on VEGF-induced tube formation and IFITM1 expression, tube formation and IFITM1 expression were evaluated in the presence or absence of $10 \mathrm{ng} / \mathrm{ml} \mathrm{VEGF}$ and/or $10 \mu \mathrm{M}$ ZON. In the ZON(-)/VEGF(+) group, the total tube length significantly increased ( 2-fold). In the $\mathrm{ZON}(+) / \mathrm{VEGF}(-)$ group, the tube length was slightly, but not significantly, decreased in comparison with that in the $\mathrm{ZON}(-) / \mathrm{VEGF}(-)$ group. The total tube length was markedly decreased in the $\mathrm{ZON}(+) / \mathrm{VEGF}(+)$ group in comparison with that in the $\mathrm{ZON}(-) / \mathrm{VEGF}(+)$ group (Fig. 4A and $\mathrm{B}$ ). Western blot analysis of IFITM1 indicated that the expression of IFITM1 was inhibited in the $\mathrm{ZON}(+) / \mathrm{VEGF}(+)$ group in comparison with that in the $\mathrm{ZON}(-) / \mathrm{VEGF}(+)$ group (Fig. 4C and D). Furthermore, RT-qPCR also indicated that IFITM1 mRNA expression decreased after treatment with

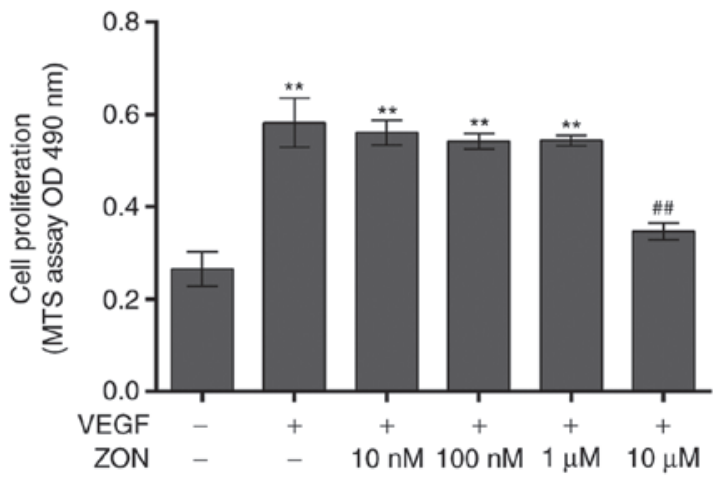

Figure 1. Effect of ZON on VEGF-induced HUVEC proliferation. HUVECs were treated with VEGF $(10 \mathrm{ng} / \mathrm{ml})$ and various concentrations of ZON $(10 \mathrm{nM}-10 \mu \mathrm{M})$. Cell proliferation was determined by an MTS assay after 3 days of culture. VEGF-induced HUVEC proliferation was significantly inhibited by $10 \mu \mathrm{M} Z \mathrm{ZON}$. Values are expressed as the mean \pm standard deviation of three independent experiment. ${ }^{* *} \mathrm{P}<0.01$ vs. control [VEGF(-)/ZON(-)]; ${ }^{\# \#} \mathrm{P}<0.01$ vs. $[\mathrm{VEGF}(+) / \mathrm{ZON}(-)]$. ZON, zoledronate; VEGF, vascular endothelial growth factor; HUVEC, human umbilical vein endothelial cell.

ZON (Fig. 4E). These results indicated that $10 \mu \mathrm{M} Z \mathrm{ZON}$ inhibited VEGF-induced tube formation activity and IFITM1 expression in HUVECs.

ZON inhibits VEGF-induced MMP-9 activation in HUVECs. To investigate whether the anti-tube formation effect of ZON was associated with MMP-9, the activation of MMP-9 was determined by zymography (Fig. 5A). The results indicated that pro MMP-9 expression was reduced by VEGF. Quantitative analysis revealed that the activated form of MMP-9 was notably increased by VEGF treatment. However, the VEGF-induced activated form of MMP-9 was slightly decreased by ZON (Fig. 5B and C). These results revealed that VEGF-induced MMP-9 activation was suppressed by ZON.
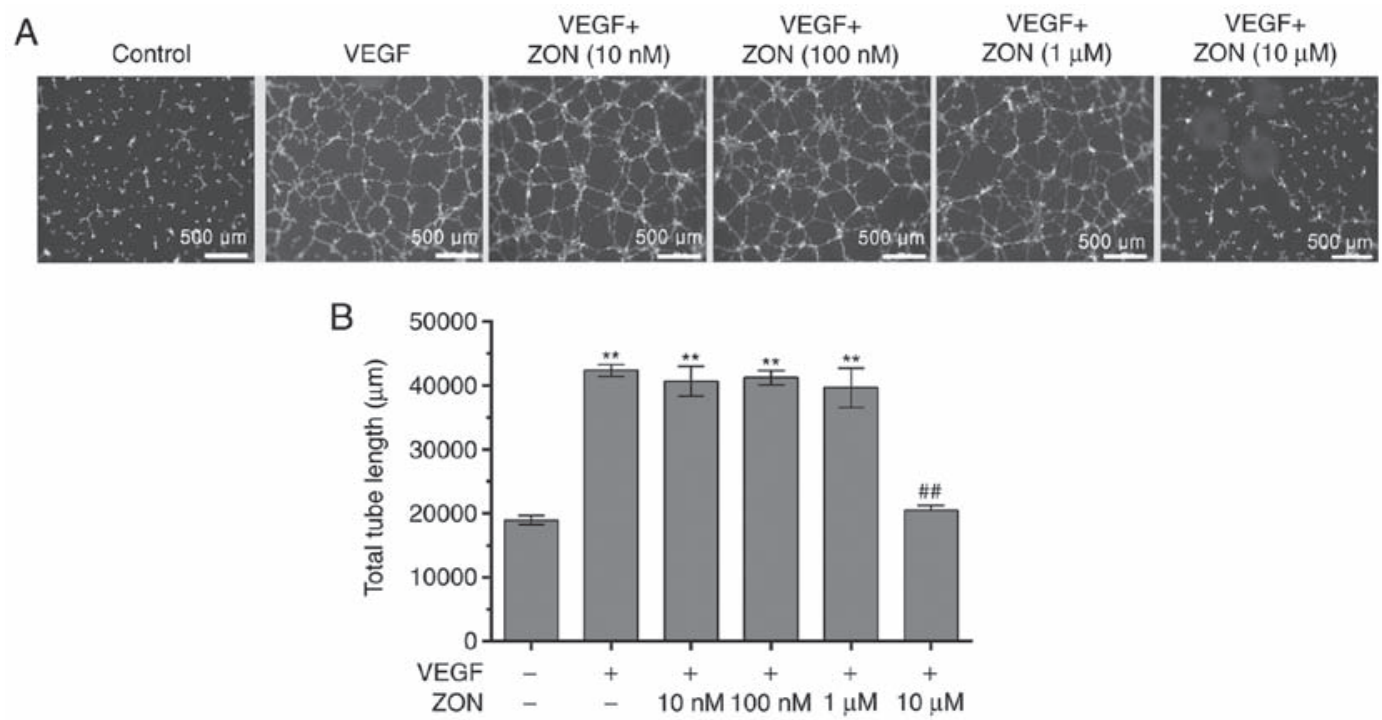

Figure 2. Effect of ZON on VEGF-induced tube formation of HUVECs. HUVECs were treated with VEGF (10 ng/ml) and various concentrations of ZON (10 nM-10 $\mu \mathrm{M})$. Capillary tube formation was determined by a Matrigel assay. (A) Images of tube formation (scale bar, $500 \mu \mathrm{m})$ and (B) quantified total length indicated that VEGF-induced tube formation was markedly inhibited by $10 \mu \mathrm{M} \mathrm{ZON}$. Values are expressed as the mean \pm standard deviation of three independent experiments. ${ }^{* *} \mathrm{P}<0.01$ vs. untreated control; ${ }^{\# \#} \mathrm{P}<0.01$ vs. [VEGF(+)/ZON(-)]. ZON, zoledronate; VEGF, vascular endothelial growth factor; HUVEC, human umbilical vein endothelial cell. 
A

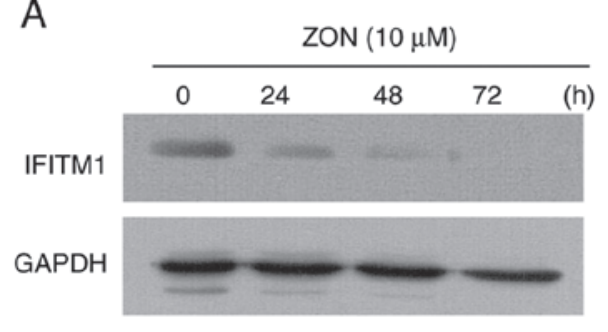

B

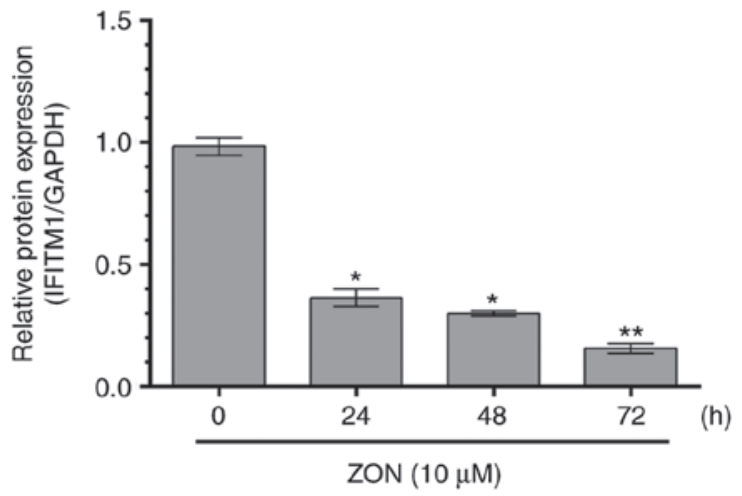

C

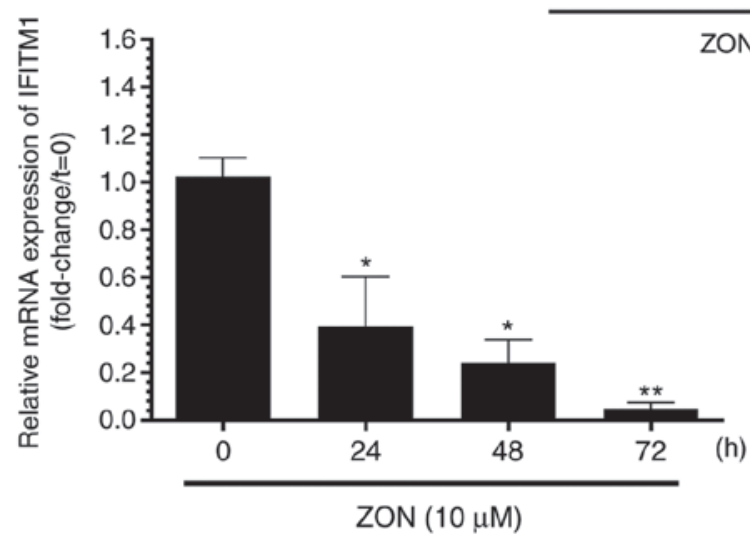

Figure 3. Effect of ZON on IFITM1 expression in human umbilical vein endothelial cells. The cells were treated with $10 \mu \mathrm{M} \mathrm{ZON}$ for 24,48 or $72 \mathrm{~h}$. (A and B) The level of IFITM1 expression was assessed by western blot analysis. (A) Representative western blot image and (B) quantified levels of the protein expression. (C) IFITM1 mRNA expression was determined by reverse transcription-quantitative polymerase chain reaction. IFITM1 expression, at the mRNA and protein level, was inhibited by treatment with $10 \mu \mathrm{M}$ ZON in a time-dependent manner. Values are expressed as the mean \pm standard deviation of three independent experiments. ${ }^{*} \mathrm{P}<0.05,{ }^{* *} \mathrm{P}<0.01$ vs. control $(0 \mathrm{~h})$. ZON, zoledronate; IFITM1, interferon-induced transmembrane protein 1.

\section{Discussion}

BRONJ is a well-known adverse effect of long-term BP therapy and represents a challenge for dentists and maxillofacial surgeons (15). Several studies have suggested the anti-angiogenic action of BP as a possible pathological mechanism of BRONJ (16). Although the anti-angiogenic effect of $\mathrm{BPs}$, including $\mathrm{ZON}$, has been assumed to be responsible for the pathology of BRONJ, the associated molecular events have remained to be fully characterized. The present study focused on the role of IFITM1 expression in the anti-angiogenic activity of ZON in HUVECs.

The present study first investigated the effect of $\mathrm{ZON}$ on endothelial cell proliferation and observed that ZON inhibited the rate of VEGF-induced endothelial cell growth. In a previous study, ZON $(\sim 64 \mu \mathrm{M})$ decreased the viability of HUVECs (17). In addition, another previous study indicated that ZON at doses of 30 and $100 \mu \mathrm{M}$ exerted a moderate effect in decreasing HUVEC viability (7). The authors demonstrated that ZON caused cellular apoptosis and sub-G1 phase arrest. In the present study, HUVEC proliferation was significantly suppressed by $10 \mu \mathrm{M} \mathrm{ZON}$ in the presence of $10 \mathrm{ng} / \mathrm{ml}$ VEGF. Although the present study did not establish the reason for the dose-dependent effect of ZON on HUVEC anti-proliferation, the results indicated that the concentration of $10 \mu \mathrm{M} \mathrm{ZON}$ inhibited VEGF-induced HUVECs proliferation, which was lower than observed in previous studies $(7,17)$.

The capillary tube formation assay is one of the most widely used in vitro assays to model the reorganization stage of angiogenesis (18). A previous study reported that $\mathrm{ZON}$ also reduced tube formation by human dermal microvascular endothelial cells (19). Fournier et al (20) also reported that treatment with ZON decreased capillary tube formation in vitro. Therefore, to determine whether ZON inhibited angiogenesis, tube formation was examined in the present study by using the Matrigel tube formation assay, which demonstrated that the tube formation capacity was inhibited by treatment with $10 \mu \mathrm{M}$ ZON. These results were also in agreement with previous studies on the anti-angiogenic effects of $\mathrm{ZON}(7,20,21)$.

A previous study (22) suggested that the inhibition of neovascularization was associated with MMP-9, VEGF, endothelial nitric oxide synthase and AKT signaling in endothelial progenitor cells. In addition, $\mathrm{ZON}$ was reported to reduce the mRNA and protein expression of VEGF in A549 non-small cell lung cancer cells (23). ZON was also demonstrated to inhibit endothelial cell adhesion and migration, and reduce Ras prenylation (24). In the present study, ZON inhibited the proliferation and capillary tube formation of HUVECs. Furthermore, it was observed that the expression of IFITM1 was reduced during ZON treatment in a time-dependent manner. Jaffe et al (25) demonstrated that IFITM1 expression and synthesis were induced by interferon- $\gamma$ and interferon- $\alpha$ in cultured human endothelial cells. In human glioma cells, knockdown of IFITM1 caused an inhibition of cell proliferation, migration and invasion (26). Tanaka et al (27) reported that IFITM1 regulated the adhesion and differentiation of mouse primordial germ cells. In addition, according to Popson et al (13), IFITM1 regulates endothelial lumen formation during angiogenesis. The study also reported that endothelial cells lacking IFITM1 failed to form stable cell-cell contacts (13). 

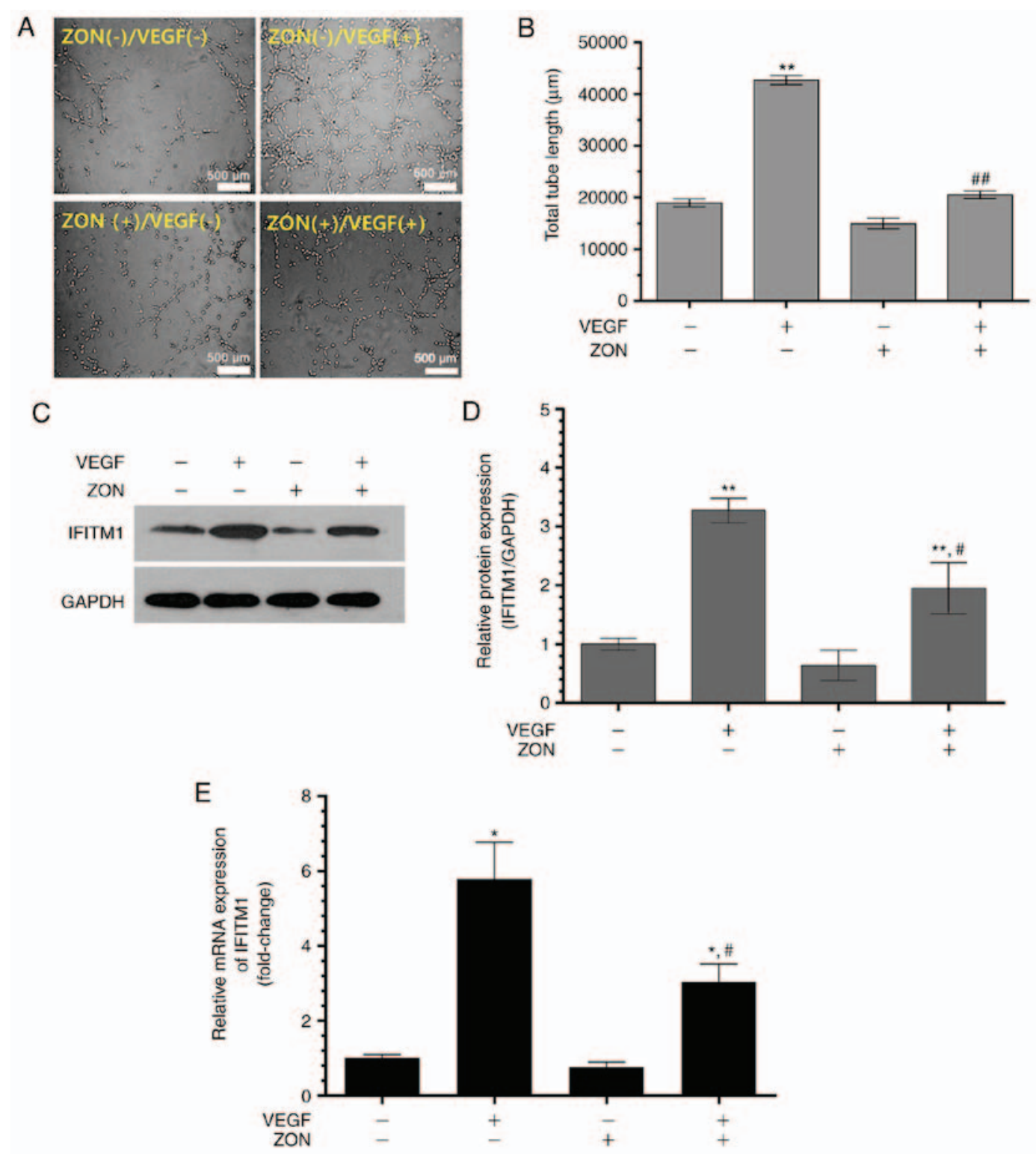

Figure 4. Effects of ZON on tube formation and IFITM1 expression. Human umbilical vein endothelial cells were treated with VEGF (10 ng/ml) and ZON $(10 \mu \mathrm{M})$. (A and B) The level of tube formation was determined via a Matrigel tube formation assay. (A) Representative images of tubes and (B) quantified total tube length in each group. The VEGF-induced tube length was markedly inhibited by ZON $(10 \mu \mathrm{M})$. (C and D) The level of IFITM1 expression was assessed by western blot analysis. (C) Representative western blot image and (D) quantified levels of the protein expression. (E) IFITM1 mRNA expression was determined by reverse transcription-quantitative polymerase chain reaction. Values are expressed as the mean \pm standard deviation of three independent experiments. ${ }^{*} \mathrm{P}<0.05$ and ${ }^{* *} \mathrm{P}<0.01$ vs. untreated control; ${ }^{\#} \mathrm{P}<0.05$ and ${ }^{\# \#} \mathrm{P}<0.01$ vs. [VEGF(+)/ZON(-)]. ZON, zoledronate; VEGF, vascular endothelial growth factor; IFITM1, interferon-induced transmembrane protein 1.
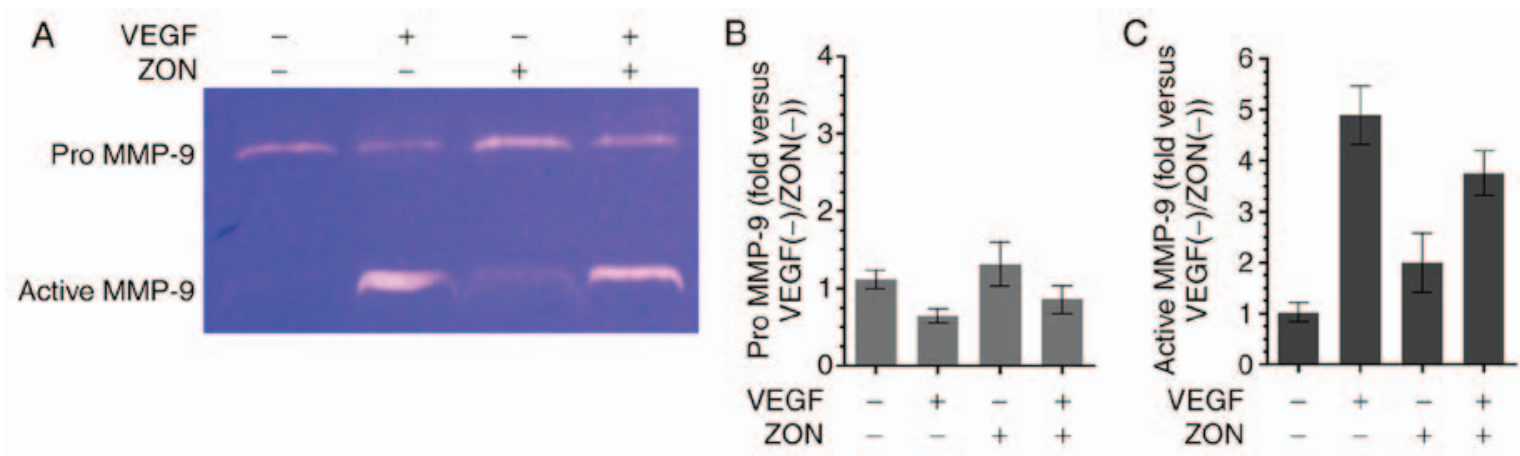

Figure 5. Effect of ZON on VEGF-induced MMP-9 activation. (A) The cells were treated with VEGF (10 ng/ml) and/or ZON (10 $\mu \mathrm{M})$ for $24 \mathrm{~h}$ and MMP-9 activation was analyzed by zymography. The results of the (B) pro-MMP-9 and (C) active MMP-9 were quantified from the zymography image using ImageJ software. ZON $(10 \mu \mathrm{M})$ notably decreased VEGF-induced MMP-9 activation. Values are expressed as the mean \pm standard deviation of three independent experiments. MMP, matrix metalloproteinase; ZON, zoledronate; VEGF, vascular endothelial growth factor. 
During angiogenesis, MMP-9 activity has important roles in the degradation of the basement membrane (28). Therefore, the present study determined MMP-9 activation using gelatin zymography. The results indicated that MMP-9 activation was markedly increased by VEGF treatment, but markedly reduced in the presence of ZON. These results suggested that the anti-angiogenesis effect of ZON may be mediated through IFITM1 and MMP-9.

Previous studies have reported the anti-proliferative effect of ZON at high doses and have suggested that ZON has potential as an anti-angiogenic agent $(7,17)$. In the present study, the anti-capillary tube formation effects of ZON $(10 \mu \mathrm{M})$ in VEGF-treated HUVECs were investigated. However, at a ZON concentration of $10 \mu \mathrm{M}$, VEGF-induced cell proliferation was also inhibited. Therefore, the possibility that these anti-angiogenic effects may be due to the cytotoxic effect of $\mathrm{ZON}$ cannot be ruled out. However, during the anti-angiogenic response, IFITM1 expression increased in response to VEGF, and VEGF-induced IFITM1 expression was also reduced by treatment with ZON. These results clearly indicate that IFITM1 is involved in this effect. Therefore, further functional studies on IFITM1 are required to identify the association between IFITM1 and anti-angiogenic activity.

\section{Acknowledgements}

This study was supported by the Basic Science Research Program through the National Research Foundation of Korea (NRF; grant nos. NRF-2015R1A2A2A01004888 and NRF-2015R1D1A1A01056748) and partially supported by the $\mathrm{X}$-mind Corps program of the NRF funded by the Ministry of Science,ICT \& Future Planning (grant no. 2017H1D8A2030449).

\section{Competing interests}

The authors declare that they have no competing interests.

\section{References}

1. Marx RE: Pamidronate (Aredia) and zoledronate (Zometa) induced avascular necrosis of the jaws: A growing epidemic. J Oral Maxillofac Surg 61: 1115-1117, 2003.

2. Marx RE, Sawatari Y, Fortin M and Broumand V: Bisphosphonate-induced exposed bone (osteonecrosis/osteopetrosis) of the jaws: Risk factors, recognition, prevention, and treatment. J Oral Maxillofac Surg 63: 1567-1575, 2005.

3. Pires FR, Miranda A, Cardoso ES, Cardoso AS, Fregnani ER, Pereira CM, Correa ME, Almeida JP, Alves Fde A, Lopes MA and de Almeida OP: Oral avascular bone necrosis associated with chemotherapy and biphosphonate therapy. Oral Dis 11: 365-369, 2005.

4. Sharma D, Ivanovski S, Slevin M, Hamlet S, Pop TS, Brinzaniuc K, Petcu EB and Miroiu RI: Bisphosphonate-related osteonecrosis of jaw (BRONJ): Diagnostic criteria and possible pathogenic mechanisms of an unexpected anti-angiogenic side effect. Vasc Cell 5: 1, 2013.

5. Petcu EB, Ivanovski S, Wright RG, Slevin M, Miroiu RI and Brinzaniuc K: Bisphosphonate-related osteonecrosis of jaw (BRONJ): An anti-angiogenic side-effect? Diagn Pathol 7: 78, 2012.

6. Otrock ZK, Mahfouz RAR, Makarem JA and Shamseddine AI: Understanding the biology of angiogenesis: Review of the most important molecular mechanisms. Blood Cells Mol Dis 39: 212-220, 2007.

7. Wood J, Bonjean K, Ruetz S, Bellahcene A, Devy L, Foidart JM, Castronovo V and Green JR: Novel antiangiogenic effects of the bisphosphonate compound zoledronic acid. J Pharmacol Exp Ther 302: 1055-1061, 2002.
8. Yamada J, Tsuno NH, Kitayama J, Tsuchiya T, Yoneyama S, Asakage M, Okaji Y, Shuno Y, Nishikawa T, Tanaka J, et al: Anti-angiogenic property of zoledronic acid by inhibition of endothelial progenitor cell differentiation. J Surg Res 151: 115-120, 2009.

9. Brass AL, Huang IC, Benita Y, John SP, Krishnan MN, Feeley EM, Ryan BJ, Weyer JL, van der Weyden L, Fikrig E, et al: The IFITM proteins mediate cellular resistance to influenza A H1N1 virus, West Nile virus, and dengue virus. Cell 139: 1243-1254, 2009.

10. Hatano H, Kudo Y, Ogawa I, Tsunematsu T, Kikuchi A, Abiko Y and Takata T: IFN-induced transmembrane protein 1 promotes invasion at early stage of head and neck cancer progression. Clin Cancer Res 14: 6097-6105, 2008.

11. Yu F, Ng SS, Chow BK, Sze J, Lu G, Poon WS, Kung HF and Lin MC: Knockdown of interferon-induced transmembrane protein 1 (IFITM1) inhibits proliferation, migration, and invasion of glioma cells. J Neurooncol 103: 187-195, 2011.

12. Pan Z, Chen S, Pan X, Wang Z, Han H, Zheng W, Wang X, Li F, Qu S and Shao R: Differential gene expression identified in uigur women cervical squamous cell carcinoma by suppression subtractive hybridization. Neoplasma 57: 123-128, 2010.

13. Popson SA, Ziegler ME, Chen X, Holderfield MT, Shaaban CI, Fong AH, Welch-Reardon KM, Papkoff J and Hughes CC: Interferon-induced transmembrane protein 1 regulates endothelial lumen formation during angiogenesis. Arterioscler Thromb Vasc Biol 34: 1011-1019, 2014.

14. Schmittgen TD and Livak KJ: Analyzing real-time PCR data by the comparative C(T) method. Nat Protoc 3: 1101-1108, 2008.

15. Vescovi P, Merigo E, Meleti M, Manfredi M, Guidotti R and Nammour S: Bisphosphonates-related osteonecrosis of the jaws: A concise review of the literature and a report of a single-centre experience with 151 patients. J Oral Pathol Med 41: 214-221, 2012.

16. Bagan JV, Murillo J, Jimenez Y, Poveda R, Milian MA, Sanchis JM, Silvestre FJ and Scully C: Avascular jaw osteonecrosis in association with cancer chemotherapy: Series of 10 cases. J Oral Pathol Med 34: 120-123, 2005.

17. Misso G, Porru M, Stoppacciaro A, Castellano M, De Cicco F, Leonetti C, Santini D and Caraglia M: Evaluation of the in vitro and in vivo antiangiogenic effects of denosumab and zoledronic acid. Cancer Biol Ther 13: 1491-1500, 2012.

18. Ponce ML: Tube formation: An in vitro matrigel angiogenesis assay. Methods Mol Biol 467: 183-188, 2009.

19. Michailidou M, Brown HK, Lefley DV, Evans A, Cross SS, Coleman RE, Brown NJ and Holen I: Microvascular endothelial cell responses in vitro and in vivo: Modulation by zoledronic acid and paclitaxel? J Vasc Res 47: 481-493, 2010.

20. Fournier P, Boissier S, Filleur S, Guglielmi J, Cabon F, Colombel M and Clezardin P: Bisphosphonates inhibit angiogenesis in vitro and testosterone-stimulated vascular regrowth in the ventral prostate in castrated rats. Cancer Res 62: 6538-6544, 2002.

21. Coxon JP, Oades GM, Kirby RS and Colston KW: Zoledronic acid induces apoptosis and inhibits adhesion to mineralized matrix in prostate cancer cells via inhibition of protein prenylation. BJU Int 94: 164-170, 2004.

22. Tsai SH, Huang PH, Chang WC, Tsai HY, Lin CP, Leu HB, Wu TC, Chen JW and Lin SJ: Zoledronate inhibits ischemia-induced neovascularization by impairing the mobilization and function of endothelial progenitor cells. PLoS One 7: e41065, 2012.

23. Di Salvatore M, Orlandi A, Bagala C, Quirino M, Cassano A, Astone A and Barone C: Anti-tumour and anti-angiogenetic effects of zoledronic acid on human non-small-cell lung cancer cell line. Cell Prolif 44: 139-146, 2011.

24. Li S and De Souza P: Ras Isoprenylation and pAkt Inhibition by zoledronic acid and fluvastatin enhances paclitaxel activity in T24 bladder cancer cells. Cancers (Basel) 3: 662-674, 2011.

25. Jaffe EA, Armellino D, Lam G, Cordon-Cardo C, Murray HW and Evans RL: IFN-gamma and IFN-alpha induce the expression and synthesis of Leu 13 antigen by cultured human endothelial cells. J Immunol 143: 3961-3966, 1989.

26. Yu F, Ng SSM, Chow BKC, Sze J, Lu G, Poon WS, Kung HF and Lin MCM: Knockdown of interferon-induced transmembrane protein 1 (IFITM1) inhibits proliferation, migration, and invasion of glioma cells. J Neurooncol 103: 187-195, 2011.

27. Tanaka SS, Yamaguchi YL, Tsoi B, Lickert H and Tam PP: IFITM/Mil/fragilis family proteins IFITM1 and IFITM3 play distinct roles in mouse primordial germ cell homing and repulsion. Dev Cell 9: 745-756, 2005.

28. Bergers G, Brekken R, McMahon G, Vu TH, Itoh T, Tamaki K, Tanzawa K, Thorpe P, Itohara S, Werb Z and Hanahan D: Matrix metalloproteinase- 9 triggers the angiogenic switch during carcinogenesis. Nature Cell Biol 2: 737-744, 2000. 